\title{
CONTROL SYSTEM FOR MEDIUM-SIZED FLYING TARGET
}

\author{
Bogusław Dołęga ${ }^{1}$, Tomasz Rogalski \\ Rzeszow University of Technology, Ul. W. Pola 2, 35-959 Rzeszow, Poland \\ E-mails.: dolbod@prz.edu.pl; ${ }^{2}$ orakl@prz.edu.pl
}

Received 30 October 2008; accepted 4 March 2009

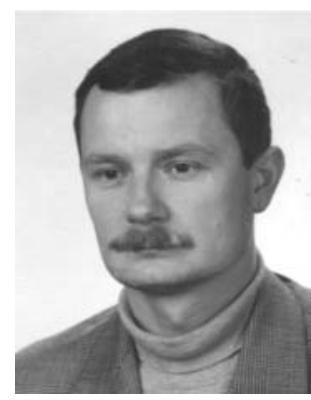

Bogusław DOŁECGA, PhD Eng

Date and place of birth: 1962 in Jaslo, Poland.

Education: Rzeszow University of Technology.

Affiliations and functions: Rzeszow University of Technology, assistant; 1994 - PhD degree from the Department of Mechanical Engineering of Rzeszow University of Technology; 1995 to present - in Department of Avionics and Control Systems at the university.

Research interests: diagnostic aircraft navigation and control systems, with a focus on the development of a control theory for online fault detection and localization methods.

Experience: co-organizer of avionics conferences.

Publications: over 40 scientific articles.

Present position: Professor Assistant in Department of Avionics and Control Systems at the university.

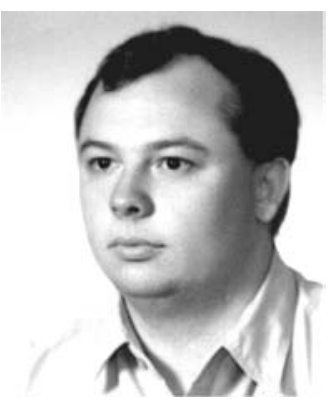

Tomasz ROGALSKI, PhD

Date and place of birth: 1972 in Tarnow, Poland.

Education: 1996 - Rzeszow University of Technology. 2004 - PhD degree.

Affiliations and functions: 1996 - present - Aviation Department of Rzeszow University of Technology.

Research interests: pilot friendly control system for small transportation plane.

Publications: about 30 articles.

\begin{abstract}
The research team from Control and Avionics Department of Rzeszow University of Technology (RUT) has been working on control systems for many types of flying objects for years. Experiences the team has had during their activity have helped create the control algorithms for a medium-size flying target (MSFT). Researchers from RUT, together with the small aviation company EUROTECH, have been working on a flying target for artillery. This paper gives a generic view of the system, including airborne and on-ground parts. But this paper mainly presents the control system that is mounted on the MSFT. The paper describes the generic conception of the control system of the flying target, including control laws used in the control system of the MSFT. Results of simulations and real flight data are also presented.
\end{abstract}

Keywords: control system, UAV.

\section{Introduction}

The Avionics and Control Department of Rzeszow University of Technology (RUT) has been working on control systems for several types of aircraft since the late 80 s of the previous century. The work has mainly concerned control systems for general aviation aircraft.
But projects involving control and navigation systems (CNS) for UAV have also been conducted. The first CNS project for UAV was started in 1996 and finished in 1999. It was called APC-4. The system consisted of two parts: airborne and on the ground one. The following modules were installed inside the aircraft: a flight computer (FC), an autonomous air data computer (ADC), an autonomous attitude and heading reference system 
(AHRS), a GPS module, actuators, and a supplementary PC-type computer to monitor the system (Fig 1).

The on-ground part of the system consisted of the computer with specialized software. It enabled preparation of missions (Fig 1).
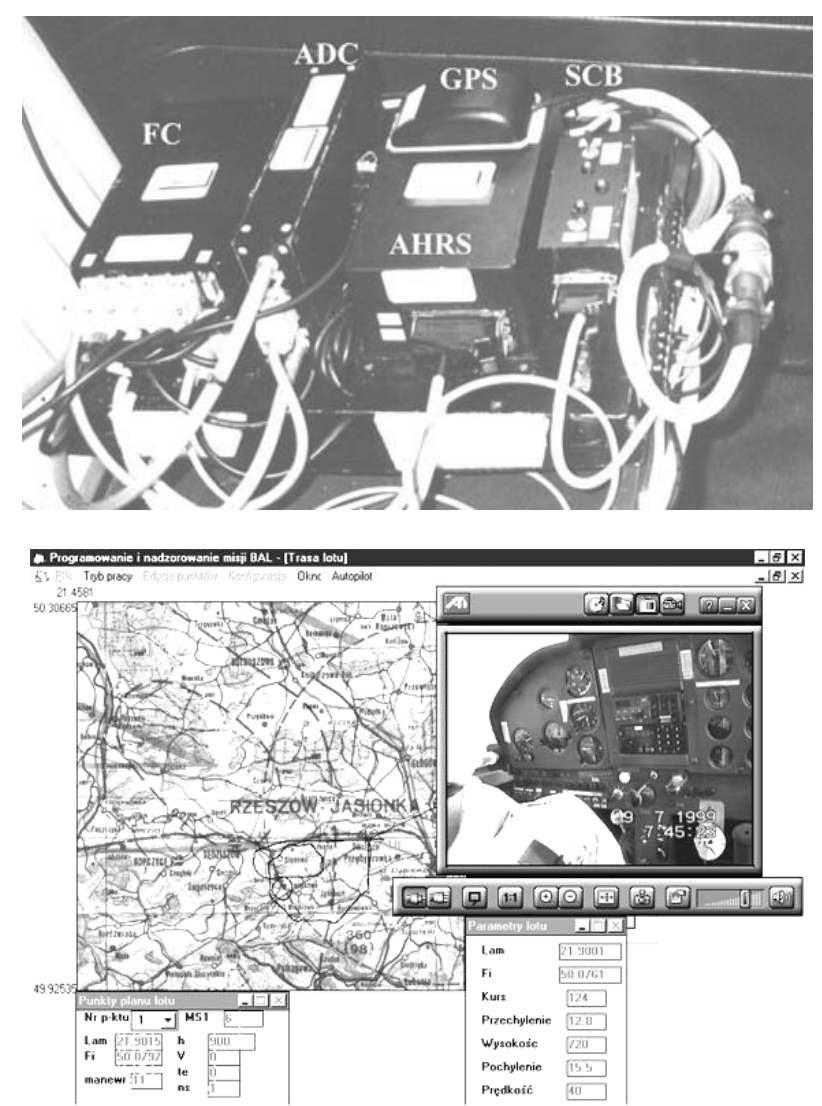

Fig 1. Modules of APC mounted in aircraft (upper); a view of the software at the ground station (lower)

The system was tested with the use of the PZL-110 Koliber, a small, four-seated general aviation plane (Tomczyk 2003). During tests, the plane guided by the APC-4 flew a series of fully automatic flights, excluding take-off and landing phases (Fig 2).

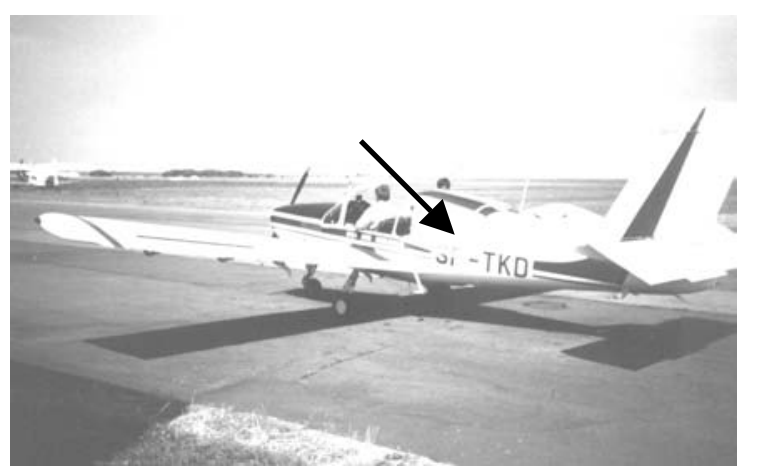

Fig 2. The experimental plane. The position of the system inside the fuselage is marked

UAV have been more and more widely used during many types of military manoeuvres and training in recent years. They are used as observers, for tactical reconnaissance tasks, and as flying targets. UAV flying as targets are used for training by air forces, artillery, and radar reconnaissance forces, to name a few. This situation has caused a demand for UAVs to appear. The Rzeszow University of Technology and EUROTECH (a small aviation company) have decided to answer the needs.

In 2005 works on the UAV was reactivated in cooperation with EUROTECH. Research teams from EUROTECH and RUT split the main goal-creation of the small flying target-into partial subtasks. EUROTECH worked on the structure of the plane, and the RUT contribution was control and navigation algorithms and software for the main FC. The on-ground station and electronic modules were prepared jointly by the partners.

\section{The plane}

The structure of the plane was developed by engineers from EUROTECH. It is fully composite, with the engine $(10 \mathrm{~kW})$ located at the front of the fuselage, a $\mathrm{V}$-shape elevator and containers for the control system, and a landing parachute located in the central section of the fuselage near the centre of gravity (Fig 3). Selected technical data of the small plane, which has been named Shogun, can be found in table 1 .

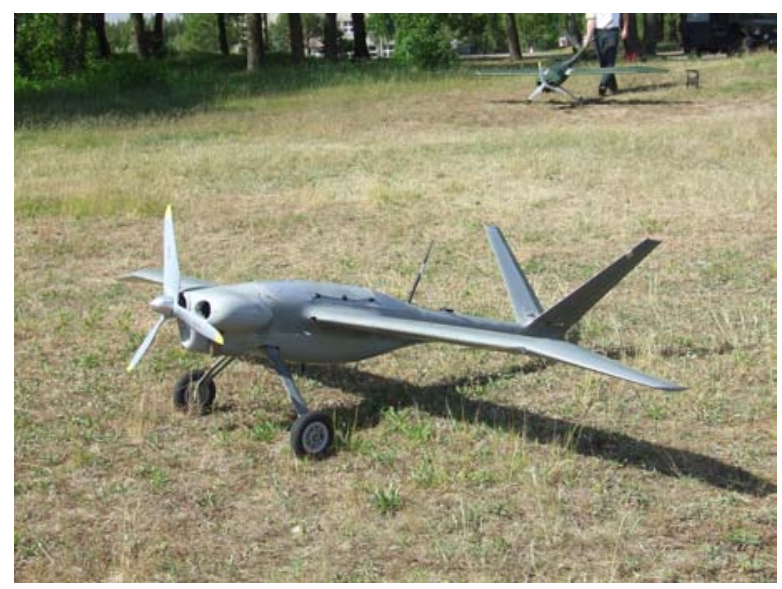

Fig 3. The plane

Table 1. Table description

\begin{tabular}{|l|l|}
\hline Wing span & $2.9[\mathrm{~m}]$ \\
\hline Length & $2.2[\mathrm{~m}]$ \\
\hline Mass & $23 \mathrm{~kg}$ \\
\hline Max. speed & more than $250 \mathrm{~km} / \mathrm{h}$ \\
\hline Cruise speed & $\sim 170 \mathrm{~km} / \mathrm{h}$ \\
\hline Stall speed & $\sim 70$ \\
\hline Duration & $1.5 \mathrm{~h}$ \\
\hline Range & $\sim 220 \mathrm{~km}$ \\
\hline
\end{tabular}

\section{Structure of the control system}

The control system for the MSFT consists of two parts: airborne elements and an on-ground control station. The ground station is an industrial computer-based system. It can handle the typical tasks performed by such systems-mission preparation, data transmission, and 
flight parameter visualization and enables manual control of the plane.

Navigation and control calculations are performed by the onboard part of the system. It consists of measurement modules (including ADC, AHRS, GPS), FC, radio link, and actuators. Moreover, a supplementary radio control system (for manual remote control) was present on board during the first phase of tests (Fig 4). The elements of the system are connected by a CAN 2B digital data bus. As a data protocol, the CAN-Aerospace standard has been selected (Stock 2004).

The air data computer is a fully autonomous module. It calculates basic air parameters: baroaltitude, air speed, and rate of climbing.

The attitude and heading reference system is not a fully autonomous module yet. It measures linear acceleration and rotation rates only. The flight computer uses these parameters and data from the ADC and GPS to calculate the useful value of attitude of the plane.

The GPS receiver is connected to the data bus via the supplementary processing unit. The SPU converts data from the GPS to the CAN-Aerospace standard. It also performs several supplementary calculations and functions as memory, informing the FC about the hardware version and configuration of the plane.

The FC module performs all calculations necessary to navigate and control the plane. It manages radio transmission to the ground station and also prepares control signals in the PWM standard for actuators.

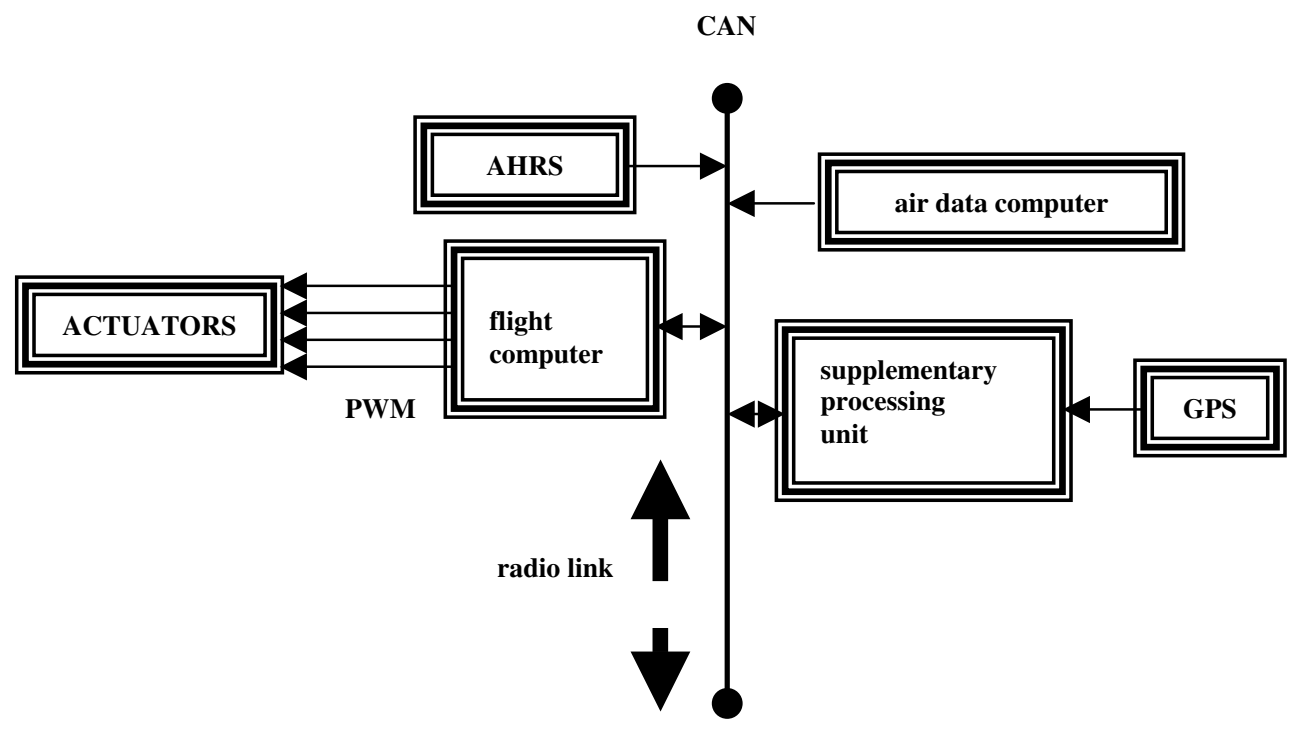

Fig 4. Logical structure of CS

\section{Control algorithms}

The control system has been prepared to offer three modes of control of the plane. This includes the following modes:

- Fully autonomous mode of control. The airplane is guided by the CS along a route prepared with the use of the ground station.

- Fully manual mode of control. The operator uses a joystick at the ground station to move the plane's control surfaces. This is doe like a pilot of a classical plane.

- Modified manual mode of control. The operator controls the plane manually but indirectly. The FC interprets the commands. On the basics of the actual flight parameters and controls coming from the operator, the FC calculates the deflections of control surfaces. The role of the operator is to set the flight parameters only. The FC guides the plane directly in a way to satisfy the operator's expectations.

The dynamics of a classical plane in steady state condition is characterized by two modes of motion: longitudinal mode and lateral mode. Classical theories of plane control say that the following two main control channels exist almost independently: pitch angle control channel and roll angle control channel. The CS therefore uses control loops in these two channels as a basis to control the flight of the plane.

\subsection{The idea behind the algorithms used}

The idea behind the control algorithms used arises from wishes to develop a controller which works as a pilot works. The author's experiences and discussions with other pilots who have more aviation practice than the author has allow him to formulate a rule which says "A pilot doesn't try to force a plane and doesn't correct its flight parameters unless it is absolutely necessary". From the point of view of this rule, actions a pilot takes while flying a plane were analyzed. Special attention was paid to both pitch angle and roll angle channel. The way pilots correct deviations of flight parameters from their demanded values was analyzed. Finally, the principle rule they used was found. It can be said that a pilot never 
corrects the flight of a plane as it goes toward the demanded state. Pitch angle stabilization process has been chosen as a sample illustrating this rule (Fig 5).

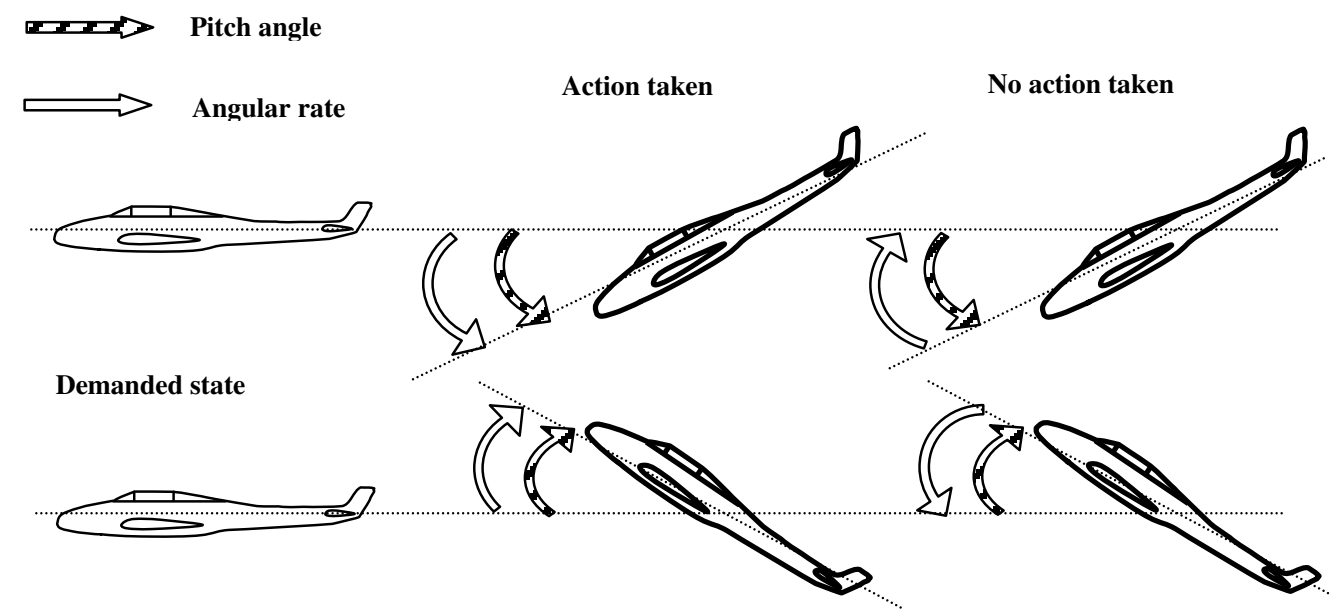

Fig 5. When pilots correct flight - as a sample pitch angle channel chosen

According to this idea, it was decided to prepare a controller which works using different rules in the states presented in figure 5. The work of that controller's channel could be mathematically defined by formula (1) in general.

$$
\operatorname{action}(t)=\left\{\begin{array}{ll}
g(e(t), \dot{e}(t)) & \text { if } \operatorname{sgn}(e(t)) \neq \operatorname{sgn}(\dot{e}(t)) \\
f(e(t), \dot{e}(t)) & \text { if } \operatorname{sgn}(e(t))=\operatorname{sgn}(\dot{e}(t))
\end{array}\right\}
$$

where $e$ is deviation of flight parameter from its demanded value.

The function $g(e(t), \dot{e}(t))$ in formula (1) can be equal to zero in special cases. Then it means that no action is taken.

\subsection{The controller}

During the work, another supplementary assumption was made. It was decided that advanced methods of synthesis of controllers would not be applied in this project. It was decided that only classical controllers as simple as possible in conjunction with knowledge of experts would be taken into considerations. Finally, the classical PID controller was selected as a starting point for calculations and analyses.

The process of creating the controller took place in three steps: A typical PID controller was created in the first step. Several non-linear elements (including saturations, death zones, etc.) were introduced into the structure of the controller in step two. The function $g(e(t), \dot{e}(t))$ from equation (1) was created and tested in the step three. Finally the extended controller named PID ${ }^{2}$ was created (2).

$$
\delta S_{P I D^{2}}(t)=\delta S_{P I D}(t)+\delta S_{D^{\prime}}(t)
$$

where $\delta \mathrm{S}_{\mathrm{PID}}{ }^{2}$ - complete control signal calculated by the controller; $\delta S_{\mathrm{PID}}$ - control signal calculated by the PID root of the controller; $\delta S_{\mathrm{D}}$ ' - control signal calculated by the supplementary channel of the controller.

Now it was necessary to define the $\delta S_{D^{\prime}}(t)$ signal in formula (2). It was decided that this function could be in the following form for the pitch and roll channel (3).

$$
\delta S_{D^{\prime}}(t)=\left\{\begin{array}{ll}
0 & \text { if } \operatorname{sgn}(e(t)) \neq \operatorname{sgn}(\dot{e}(t)) \\
f(e(t), \dot{e}(t)) & \text { if } \operatorname{sgn}(e(t))=\operatorname{sgn}(\dot{e}(t))
\end{array}\right\}
$$

where $e(t)$ is deviation of pitch angle in pitch channel or deviation of roll angle in roll channel.

Formula (3) informs us that no correcting action is taken if the aircraft's flight parameters vary to lead the plane to the demanded state.

The analyses presented in this paper concern pitch and roll angle control processes. The process of creating the controller must be strictly connected with physical rules governing airplane dynamics. The control signal $\delta S_{D^{\prime}}(t)$ can be created according to different rules, including linear and nonlinear formulas, expert knowledge, etc.

In the first attempt, it was assumed that the control signal $\delta S_{D^{\prime}}(t)$ should be enough to stop the rotation of the plane around the $\mathrm{X}$-axis or $\mathrm{Y}$-axis. Data about the dynamics of the plan were therefore necessary. The process of identifying of the dynamics of the airplane had to be performed.

\subsection{Model of airplane dynamics}

The plane was equipped with measurement devices which enabled the identification of its dynamics in both pitch and roll modes of motion. A series of test flights 
took place. On the basis of the data acquired, the roll mode of lateral plane motion and short period mode of longitudinal plane motion were identified. The transfer function found for the roll mode had the following form (4).

$$
G_{\text {roll }}(s)=\frac{p(s)}{\delta_{a}(s)}=\frac{K_{p}}{\left(T_{\text {roll }} s+1\right)}=\frac{-2}{1.1 s+1},
$$

where $\mathrm{p}-$ roll rate $(\mathrm{deg} / \mathrm{s}), \delta_{\mathrm{a}}-$ deflection of ailerons (percent of range).

Data acquired during the test flights showed that the dynamic of the plane in the pitch channel can be described in a simpler form in practice than the theory says (Fig 6).
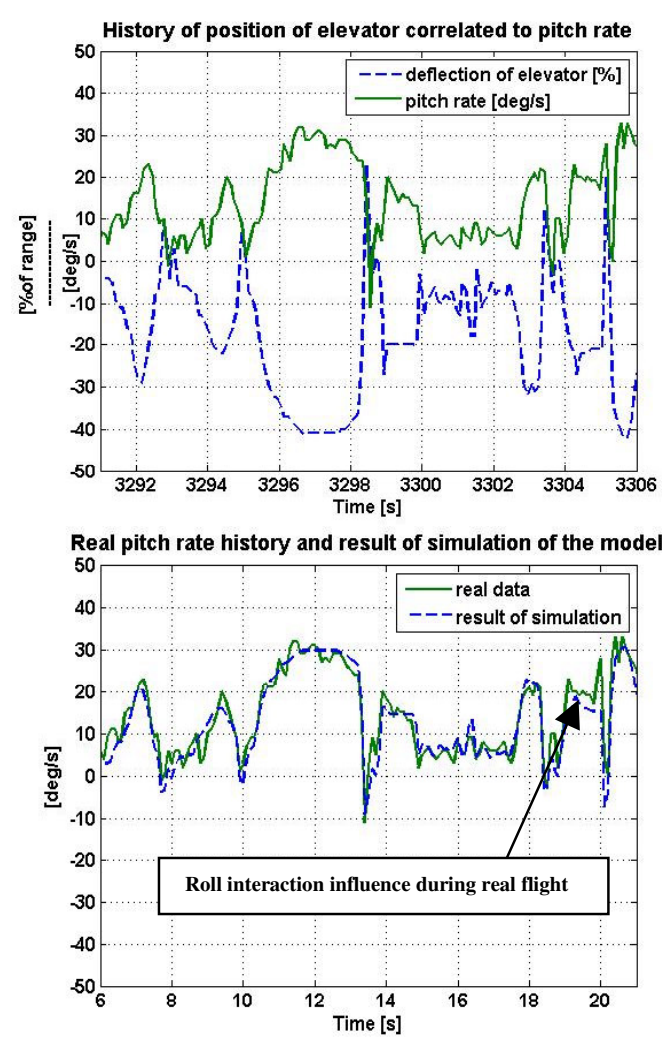

Fig 6. The history of deflection of ailerons and pitch rate (upper); real data and results of simulation of the model (lower)

The small plane used in this project is characterized by higher efficiency of control surfaces than the typical plane. This phenomenon meant that the short period mode of longitudinal modes of motion can be modelled with formula (5) instead of the formula normally used (McRuer et al. 1990).

$$
G_{s p}(s)=\frac{q(s)}{\delta_{e}(s)}=\frac{K_{q}}{\left(T_{s p}{ }^{2} s^{2}+2 \xi_{s p} T_{s p} s+1\right)}
$$

where $\mathrm{q}-$ pitch rate $(\mathrm{deg} / \mathrm{s}) \delta_{\mathrm{e}}-$ deflection of elevator (percent of range).
The results of the simulation of this model for the following parameters $\left(K_{q}=0.73, T_{s p}=0.05 \xi_{s p}=0.7\right)$ are presented on figure 6 .

\subsection{Equations of controller's supplementary controls for pitch and roll channels}

It was mentioned in paragraph 4.2 that parameters of supplementary channels of extended PID controllers should be constructed in order to stop the rotation of the plane around either the $\mathrm{X}$-axis or the $\mathrm{Y}$-axis. In consideration of the dynamics of the plane defined by formulas (2), (3), (4) and (5), the control signals generated by the extra controller's channels had the following form (6), (7):

$$
\begin{aligned}
& f(e(t), \dot{e}(t))_{\text {roll }}(t)=\frac{p(t)}{K_{p}} \\
& f(e(t), \dot{e}(t))_{\text {pitch }}(t)=\frac{q(t)}{K_{q}}
\end{aligned}
$$

\section{Test flight}

The control algorithms presented in the previous section of this paper were tested in several ways. Tests started from computer simulations with the use of a specialized laboratory stand (Dolega et al. 2004). Simulations were performed in accordance with hardware-in-the-loop-simulation technology. The positive results of simulations enabled us to start testing the control algorithms in real flight conditions.

Flight tests were not performed with the use of the final version of the plane at the beginning. The mediumsized model was used in the first series of tests. A model that had a 2.5-metre wingspan and was powered by an internal combustion engine was used during the second series of flying tests. During the third series of flying tests, the final small aircraft was used.

Experimental flights covered several tests, including attitude stabilization tests, tests of navigation procedures, tests of altitude stabilization, and tests of completely autonomous flight.

This paper focuses on selected algorithms of attitude stabilization in principle. Algorithms of navigation and results of autonomous flight are not presented in the details.

Tests included flights when the classical PID controller was responsible for pitch and roll stabilization and flights when the extended PID was used. Sample results are collected and presented on figure 7 . The history of the pitch angle stabilization process during the flight at constant altitude with the use of two kinds of controllers is plotted there. 

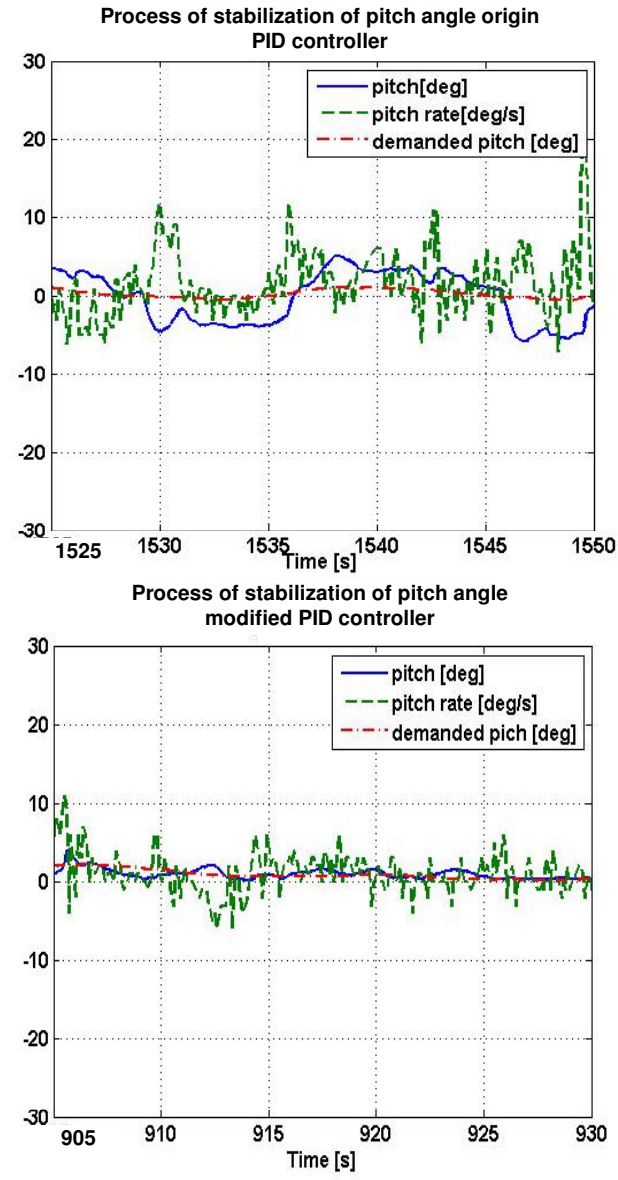

Fig 7. Process of pitch angle stabilization by pure PID controller (upper) and extended PID controller (lower)

Two experiments were conducted in few minutes so atmospheric conditions were that same. Flight with the use of extended PID controller was characterized with less deviation of pitch angle. Oscillations of pitch angle were scientifically reduced. Less variations of pitch rate when extended PID was used testified the flight were less dynamic (flight was calmer).

\section{Conclusions}

The paper presents the results of work on control algorithms for a MSFT. One of the goals of the research performed during this work was to prepare a controller, which could control the attitude of a plane well enough for the typical operational flight of a projected flying target. The simple solution based upon a classical controller and knowledge of experts was used. Test flights showed that the methodology used brought positive results. The use of the extended PID controller increased control quality as a result.

The results of research confirmed that it is not really necessary to apply very sophisticated theories to increase control qualities in practice. Simple but smart solutions can give quite good results often.

\section{References}

Dolega B.; Rogalski T. 2004. The new conception of the laboratory testing of the FBW control system. Aircraft Engineering and Aerospace Technology, 76 (3): 293-298. ISSN 0002-2667.

McRuer D.; Ashkens I.; Graham D. 1990. Aircraft dynamics and automatic control. Princeton University Press.

Stock, M. 2004. Can Aerospace, revision 1.6. In Stock Flight Systems. Schutzenweg, Berg, Germany.

Tomczyk, A. 2003. In-flight tests of navigation and control system of unmanned air vehicle. Aircraft Engineering and Aerospace Technology, 75(6): 581587.

\section{VALDYMO SISTEMA VIDUTINIO DYDŽIO SKRAIDANTIEMS TAIKINIAMS}

\section{B. Dołęga, T. Rogalski}

S a n tra k a

Ržešovo technologijos universiteto Valdymo ir kontrolès departamento tyrëjų grupė keletą metų dirba su ịvairių tipų orlaivių valdymo sistemomis. Turimas grupès patyrimas panaudotas kuriant valdymo sistemas vidutinio dydžio taikiniams. RUT tyrejjai kartu su maža aviacijos įmone EUROTECH dirba su skraidančiais taikiniais artilerijai. Straipsnyje pateikiama bendra sistemos apžvalga, iskaitant skrendančias ir žemėje esančias dalis. Pagrindinis dèmesys straipsnyje skiriamas valdymo sistemai, sumontuotai skrendančiame taikinyje. Pateikiama bendra skrendančio taikinio valdymo sistemos koncepcija, įskaitant valdymo dèsnius, taikomus skrendančio taikinio valdymo sistemoje. Taip pat pateikiami modeliavimo ir realių skrydžių rezultatai.

Reikšminiai žodžiai: valdymo sistema, bepiločiai orlaiviai. 